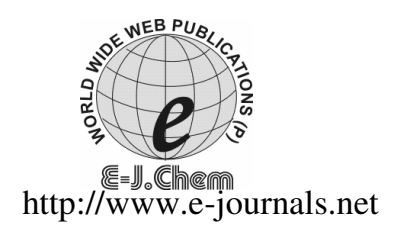

ISSN: 0973-4945; CODEN ECJHAO

E-Journal of Chemistry

2011, 8(4), 1979-1985

\title{
$H$-Point Standard Addition Method for Simultaneous Determination of Eosin and Erytrosine
}

\author{
AMANDEEP KAUR and USHA GUPTA* \\ Department of Chemistry \\ Punjabi University, Patiala-147002, Punjab, India \\ guptausha57@yahoo.com
}

Received 1 March 2011; Accepted 28 April 2011

\begin{abstract}
A new, simple, sensitive and selective $H$-point standard addition method (HPSAM) has been developed for resolving binary mixture of food colorants eosin and erythrosine, which show overlapped spectra. The method is based on the complexation of food dyes eosin and erythrosine with $\mathrm{Fe}(\mathrm{III})$ complexing reagent at $\mathrm{pH} 5.5$ and solubilizing complexes in triton $\mathrm{x}-100$ micellar media. Absorbances at the two pairs of wavelengths, 540 and $550 \mathrm{~nm}$ (when eosin acts as analyte) or 518 and $542 \mathrm{~nm}$ (when erythrosine act as analyte) were monitored. This method has satisfactorily been applied for the determination of eosin and erythrosine dyes in synthetic mixtures and commercial products.
\end{abstract}

Keywords: HPSAM, Eosin, Erythrosine, Simultaneous Determination and Fe(III)

\section{Introduction}

The term color additive can be applied to any dye, pigment or other substance artificially made or obtained from a vegetable, animal, mineral, or another natural source. Color ${ }^{1}$ is a vital constituent of food and probably the first characteristic perceived by the human senses. Food coloring ${ }^{2}$ is any substance that is added to food or drink to change its color probably, for economic reasons. These dyes are used to supplement and enhance natural colors ${ }^{3}$ destroyed during processing or storage and substantially increase the appeal and acceptability of food stuffs.

Eosin ${ }^{4}$ is an acidic florescent red dye resulting from the action of bromine on fluorescein. A red crystalline powder used in textile dyeing, ink manufacturing and in coloring gasoline, red sodium or potassium salt of this powder is used in biology to stain cells ${ }^{5}$ and cytoplasm, collagen and muscle fibers for examination under the microscope and in cosmetic. It causes irritation and burning sensations of mouth, nausea, vomiting and it is carcinogenic in nature.

Erythrosine ${ }^{6}$ is a reddish - pink synthetic dye, which is water soluble and most popularly used as a food coloring agent and a host of other applications ${ }^{7}$ such as printing inks, a dental 
plaque disclosing agent. It is also used in drugs and cosmetics, cocktails, tinned fruits, garlic sausage, scotch eggs and snack foods. It is highly toxic, causing various types of allergies, thyroid activities, anemia ${ }^{8}$ and DNA damage behavior. It is also carcinogenic in nature.

In 1988, Bosch-Reig and Campins-Falco ${ }^{9-12}$ presented a new technique, the $H$-point standard addition method (HPSAM), with which two species ${ }^{13,14}$ with overlapping spectra can be determined simultaneously. The basis of the method permits the determination of two species with extensively overlapped spectra. The method ${ }^{15-19}$ is based on selecting two pair of independent variable in such a way that in each pair, the analytical signal, due to one of the species, is constant and for another one as different as possible. In this present work, $H$-point standard addition method (HPSAM) has been developed for simultaneous determination of eosin and erythrosine with $\mathrm{Fe}(\mathrm{III})$ as a complexing agent.

\section{Experimental}

Digitized UV-Vis absorption spectra were recorded using a Shimadzu 1800 spectrophotometer, with $10 \mathrm{~mm}$ quartz cell and measurements of $\mathrm{pH}$ were made with digital century $\mathrm{pH}$-meter $\mathrm{C}_{\mathrm{p}}-901$ using a combined glass electrode.

\section{Reagents}

All reagents used were of analytical reagent grade unless otherwise stated and double distilled water was used throughout the experiment. Stock solution of eosin and erythrosine were prepared in double distilled water. Further dilutions were made as and when required. A $0.1 \%$ (w/v) solution of $\mathrm{Fe}(\mathrm{III})$ was prepared in double distilled water. A buffer solution of $\mathrm{pH} 5.5$ was prepared by mixing $0.2 \mathrm{M}$ acetic acid and $0.2 \mathrm{M}$ sodium acetate solution and $0.5 \%(\mathrm{v} / \mathrm{v})$ triton $\mathrm{x}-100$ solution was prepared in hot double distilled water.

\section{Procedure}

\section{BIANRY - HPSAM}

Appropriate amounts of eosin and erythrosine sample solution were taken in a beaker and $\mathrm{pH} 5.5$ was adjusted by adding $2.0 \mathrm{~mL}$ sodium acetate/ acetic acid buffer solution, $3.0 \mathrm{~mL}$ of $0.1 \% \mathrm{Fe}(\mathrm{III})$ solution and $2.0 \mathrm{~mL}$ of $0.5 \%$ triton $\mathrm{x}-100$ were added and then standard additions of eosin or erythrosine when erythrosine or eosin was selected as the interferent were made respectively. The volume was made up to the $10.0 \mathrm{~mL}$ with double distilled water. A portion of this solution was taken and recorded the full range spectrum against the reagent blank and selected a pair of wavelength $(550$ and $540 \mathrm{~nm})$ for eosin as analyte and (542 and $518 \mathrm{~nm}$ ) for erythrosine as analyte.

\section{Results and Discussion}

Absorption spectra of $\mathrm{Fe}(\mathrm{III})$ complexes with eosin and erythrosine overlap as shown in Figure 1. Since the spectral bands of complexes overlaps the simultaneous determination of eosin and erythrosine is possible only using $H$-point standard addition method.

\section{Effect of $\mathrm{pH}$}

The effect of pH 3.5 - 9.5 on absorbance of Eosin - Fe(III) and erythrosine - Fe(III) is shown in Figure 2. Eosin-Fe(III) complex showed maximum and constant absorbance in the $\mathrm{pH}$ range $3.5-6.0$ and it decreased at higher $\mathrm{pH}$. Absorbance of Erythrosine-Fe(III) complex showed maximum absorbance at $\mathrm{pH} 5.5$, therefore $\mathrm{pH} 5.5$ was selected for simultaneous determination of eosin and erythrosine. 


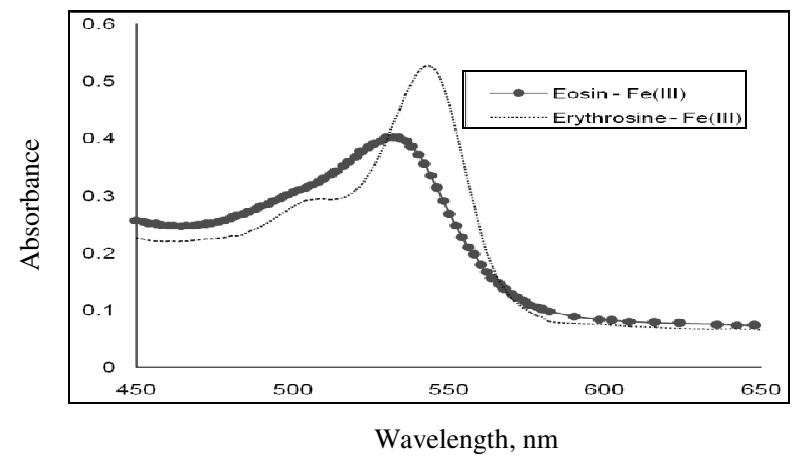

Figure 1. Absorbance spectra of (a) Eosin- Fe(III) complex (b) Erythrosine - Fe(III) complex, in $0.5 \%$ triton $\mathrm{x}-100$ at $\mathrm{pH} 5.5$

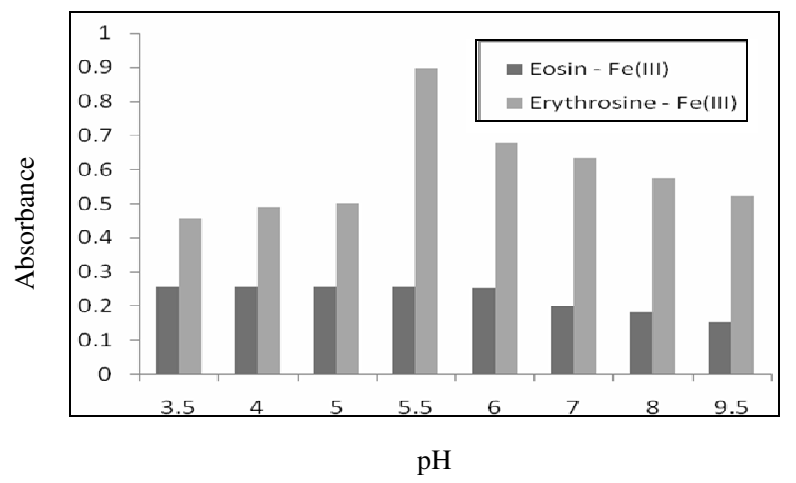

Figure 2. Effect of pH on the absorbance of (1) Eosin - Fe(III) and (2) Erythrosine Fe(III) complex

\section{Effect of surfactant}

Various surfactants such as triton $\mathrm{x}-100$, Tween-20, Tween-80, cetylpyridinium bromide (CPB), sodium lauryal sulphate (SLS) and cetyltrimethylammonium bromide (CTAB), were tried as solubilizing agents. Both for eosin-Fe(III) and erythrosine-Fe(III) complexes absorbance was maximum with triton $\mathrm{x}-100$. So, for simultaneous determination of eosin and erythrosine, $2.0 \mathrm{~mL}$ of $0.5 \%$ triton $\mathrm{x}-100$ was selected as the working micellizing agent for further studies. Effect of different surfactant is shown in Figure 3.

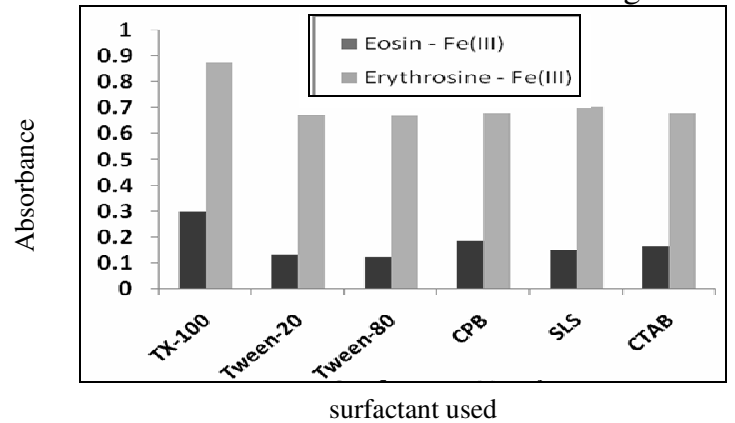

Figure 3. Effect of different surfactants on absorbance of eosin - Fe(III) and Erythrosin - Fe(III) complexes. 


\section{Effect of reagent concentration}

Effect of different amounts of Fe(III) on the absorbance of eosin-Fe(III) and erythrosine$\mathrm{Fe}(\mathrm{III})$ complexes was studied. The maximum absorbance in both the cases was observed when $1.5 \mathrm{~mL}$ of $0.1 \% \mathrm{Fe}(\mathrm{III})$ was used for individual calibration. To ensure the complete complexation for simultaneous determination of eosin and erythrosine, $3.0 \mathrm{~mL}$ of $0.1 \%$ $\mathrm{Fe}(\mathrm{III})$ was used. Effect of different amounts of $0.1 \% \mathrm{Fe}(\mathrm{III})$ is shown in Figure 4.

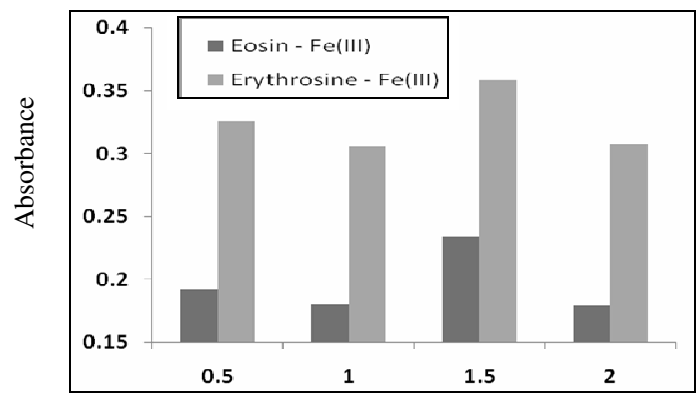

Different volumes of $0.1 \% \mathrm{Fe}(111)$

Figure 4. Effect of different volume of $0.1 \% \mathrm{Fe}$ (III) on the absorbance of eosin - Fe(III) and erythrosine - Fe(III) complex

\section{Applying binary-HPSAM}

When eosin is selected as the analyte, many pairs of wavelengths showing the same absorbance for the Erythrosine - Fe(III) complex were possible. Different experiments for evaluating HPSAM for the determination of eosin and erythrosine in a series of samples containing fixed amounts of eosin with different amounts of erythrosine (Figure 5) or fixed amounts of erythrosine with different amounts of eosin (Figure 6) were carried out by addition of eosin standard solutions. By adding standard solutions of erythrosine, we also tested the applicability of HPSAM in determining eosin and erythrosine in a series of samples containing fixed amounts of erythrosine together with different amounts of eosin (Figure 7) or fixed amounts of eosin together with different amounts of erythrosine (Figure 8). The results show that eosin and erythrosine contents in the samples have been determined accurately.

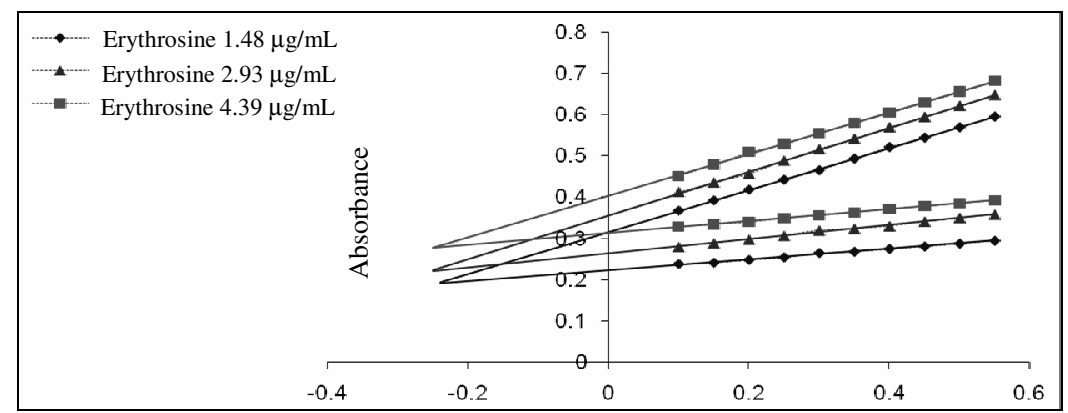

Eosin added, $\mu \mathrm{g} / \mathrm{mL}$

Figure 5. Plot of $H$-point standard addition method for simultaneous determination of fixed amounts of eosin concentration $(3.12 \mu \mathrm{g} / \mathrm{mL})$ and different amounts of erythrosine, when different standard eosin solutions are added 


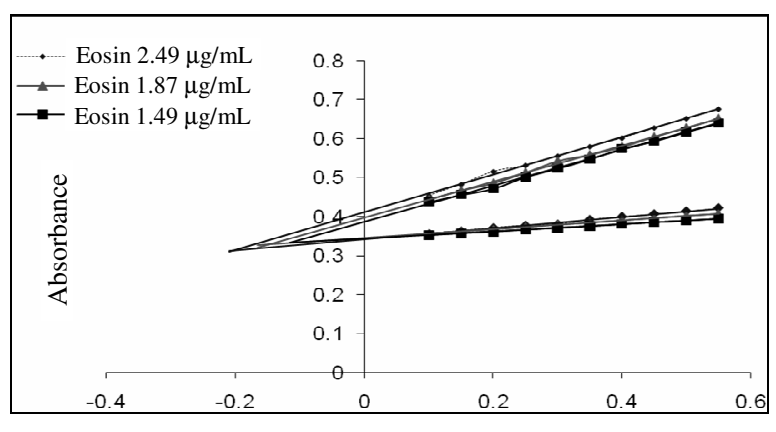

Eosin added, $\mu \mathrm{g} / \mathrm{mL}$

Figure 6. Plot of $H$-point standard addition method for simultaneous determination of fixed amounts of erythrosine concentration $(2.93 \mu \mathrm{g} / \mathrm{mL})$ and different amounts of eosin, when different standard eosin solutions are added

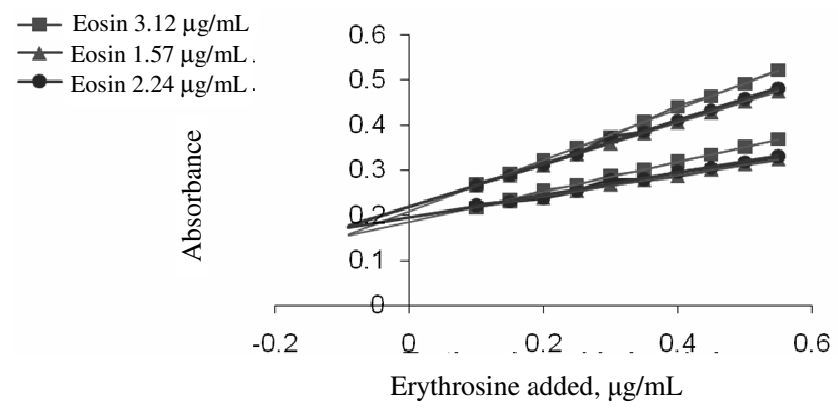

Figure 7. Plot of $H$-point standard addition method for simultaneous determination of fixed amount of erythrosine concentration $(1.46 \mu \mathrm{g} / \mathrm{mL})$ and different amounts of eosin, when different standard erythrosine solutions are added

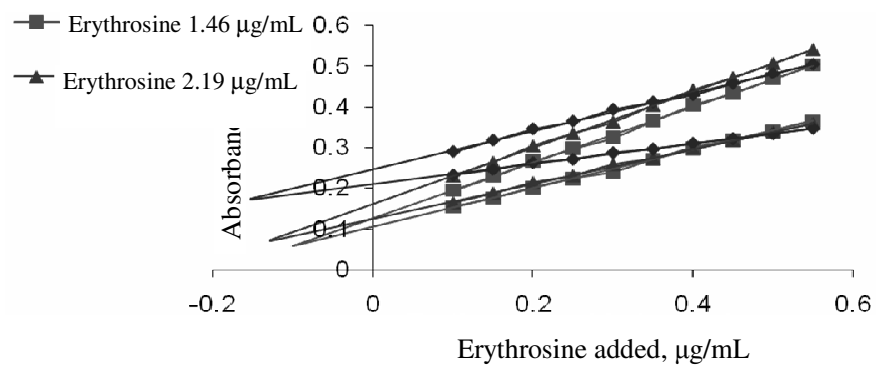

Figure 8. Plot of $H$-point standard addition method for simultaneous determination of fixed amounts of eosin concentration $(1.24 \mu \mathrm{g} / \mathrm{mL})$ and different amounts of erythrosine, when different standard erythrosine solutions are added

\section{Accuracy and precision}

Several synthetic samples with different concentration ratio of erythrosine and eosin were analyzed using HPSAM. The concentration ranges of eosin and erythrosine for construction of calibration graphs were $1.24-6.86 \mu \mathrm{g} \mathrm{mL}^{-1}$ and $1.46-6.59 \mu \mathrm{g} \mathrm{mL}^{-1}$ respectively. Several synthetic samples with different concentration ratios of eosin and erythrosine were analyzed using HPSAM. The results are given in Table 1. 
Table 1. Results of several experiments for analysis of eosin and erythrosine (Ery) in synthetic samples by HPSAM

\begin{tabular}{ccccccccc}
\hline \multirow{2}{*}{$\mathrm{A}-\mathrm{C}$ Equation } & \multicolumn{2}{c}{$\mathrm{r}^{2} \begin{array}{c}\text { Present, } \mu \mathrm{g} / \mathrm{mL} \\
\text { Eosin, }\end{array}$} & \multicolumn{2}{c}{ Found, $\mu \mathrm{g} / \mathrm{mL}$} & \multicolumn{2}{c}{$\%$ Recovery } \\
Eosin, Ery & Eosin, Ery \\
\hline $\mathrm{A}_{550}=0.0447 \mathrm{C}_{\mathrm{i}}+0.4439$ & 0.9815 & 3.12 & 3.66 & 3.05 & 3.61 & 97.75 & 98.63 \\
$\mathrm{~A}_{540}=0.0283 \mathrm{C}_{\mathrm{i}}+0.3938$ & 0.9818 & & & & & & \\
$\mathrm{~A}_{550}=0.0351 \mathrm{C}_{\mathrm{i}}+0.4909$ & 0.9711 & 3.74 & 3.66 & 3.74 & 3.64 & 100 & 99.45 \\
$\mathrm{~A}_{540}=0.0190 \mathrm{C}_{\mathrm{i}}+0.4312$ & 0.9565 & & & & & & \\
$\mathrm{~A}_{550}=0.0373 \mathrm{C}_{\mathrm{i}}+0.5504$ & 0.9823 & 4.36 & 4.39 & 4.35 & 4.38 & 99.77 & 99.77 \\
$\mathrm{~A}_{540}=0.0214 \mathrm{C}_{\mathrm{i}}+0.4812$ & 0.9554 & & & & & & \\
$\mathrm{~A}_{550}=0.0371 \mathrm{C}_{\mathrm{i}}+0.5774$ & 0.999 & 4.99 & 4.39 & 4.94 & 4.36 & 98.99 & 99.31 \\
$\mathrm{~A}_{540}=0.0214 \mathrm{C}_{\mathrm{i}}+0.4997$ & 0.9855 & & & & & & \\
$\mathrm{~A}_{550}=0.0349 \mathrm{C}_{\mathrm{i}}+0.4663$ & 0.9955 & 5.24 & 1.75 & 5.24 & 1.74 & 100 & 99.42 \\
$\mathrm{~A}_{540}=0.0204 \mathrm{C}_{\mathrm{i}}+0.3902$ & 0.9651 & & & & & & \\
$\mathrm{~A}_{550}=0.0352 \mathrm{C}_{\mathrm{i}}+0.5479$ & 0.9656 & 5.24 & 3.22 & 5.22 & 3.22 & 99.61 & 100 \\
$\mathrm{~A}_{540}=0.0206 \mathrm{C}_{\mathrm{i}}+0.4717$ & 0.9504 & & & & & & \\
$\mathrm{~A}_{550}=0.035 \mathrm{C}_{\mathrm{i}}+0.6738$ & 0.9813 & 3.99 & 5.57 & 3.71 & 5.52 & 92.98 & 99.10 \\
$\mathrm{~A}_{540}=0.0197 \mathrm{C}_{\mathrm{i}}+0.6172$ & 0.9128 & & & & & & \\
$\mathrm{~A}_{550}=0.045 \mathrm{C}_{\mathrm{i}}+0.7035$ & 0.994 & 3.99 & 6.59 & 3.99 & 6.43 & 100 & 97.57 \\
$\mathrm{~A}_{540}=0.0303 \mathrm{C}_{\mathrm{i}}+0.6448$ & 0.9941 & & & & & & & \\
\hline
\end{tabular}

\section{Application of the method}

\section{Determination of eosin and erythrosine in lipstick}

Lipstick was grounded with a mortar and pestle, $1.0 \mathrm{~g}$ sample (lipstick), digested with mixture of $\mathrm{HNO}_{3}: \mathrm{H}_{2} \mathrm{SO}_{4}$ taken in ratio of $(2: 1)$. The mixture was heated up to $100{ }^{\circ} \mathrm{C}$ for one hour and then cooled. After cooling $5 \mathrm{~mL}$ of double distilled water was added to the sample and mixed. The residue was filtered, diluted with double distilled water up to standard volume. The sample solution was then analyzed by the developed procedure .The results are given in Table 2.

Table 2. Determination of eosin and erythrosine in different samples by HPSAM

\begin{tabular}{ccccc}
\hline \multicolumn{4}{c}{ Concentration, $\mu \mathrm{gmL}^{-1}$} \\
\hline \multirow{2}{*}{ Sample } & \multicolumn{2}{c}{ Present, $\mu \mathrm{g} / \mathrm{mL}$} & \multicolumn{2}{c}{ Found, $\mu \mathrm{g} / \mathrm{mL}$} \\
& Eosin & Erythrosine & Eosin & Erythrosine \\
\hline Lipstick $^{*}$ & 3.02 & 4.10 & 2.89 & 4.14 \\
Ink & 4.59 & 3.27 & 4.61 & 3.35 \\
Fruit Drink $^{* *}$ & 5.12 & 5.75 & 5.22 & 5.81 \\
\hline
\end{tabular}

Lipstick $^{*}$ - Locally available in market (cheery color). Fruit Drinks ${ }^{* *}$ - locally available in market

\section{Determination of eosin and erythrosine in ink and fruit drink}

$25 \mathrm{~mL}$ of the sample was transferred to a $50 \mathrm{~mL}$ volumetric flask and made volume up to the mark with double distilled water and solution was analyzed by developed procedure. The good agreement between the obtained results and the known amounts in the sample indicate the successful applicability of the method. The results are given in Table 2. 


\section{Conclusion}

Simultaneous determination of eosin and erythrosine without the use of any expensive instrument has been done. This reduces the cost of applied method. No extraction step is required as determination has been done in micellar media and hence the use of toxic and carcinogenic organic solvents is avoided. Micellar systems solublized the insoluble complex, and eliminated the need of organic solvents extraction step in analysis. This reduces the toxicity of the applied method.

\section{References}

1. Jeannine Delwiche F, The impact of perceptual interactions on perceived flavor, Food Quality and Preference, 2004, 15, 137-146.

2. Food Additives and Hyperactive Behavior in Children in the Community a Randomized Double Blinded, Placebo Controlled Trial, Lancet, Sep, 2007.

3. Branen A L, Davidson P M and Salminen S, Food Additives Academic New York, 1989.

4. Susan Budavari, Ed., The Merck Index, 1996, 12.

5. Lillie R D, Williams \& Wilkins, Baltinore M D, U.S.A, Conn`s Biological stains, 1992.

6. Edward Gurr, Syhthetic Dyes in Biology, Medicine and Chemistry, 1997.

7. Atayan V Z, Sumina E G and Shtykov S N, J Anal Chem., 2003, 58, 7.

8. Jain, Rajeev, Meenakshi, Bhargava and Sharma, Nidhi, Ind Eng Chem Res., 2003, 42, 243.

9. Bosch-Reig F and Campins-Falco P, Analyst, 1998, 113, 1011.

10. Bosch-Reig F and Campins-Falco P, Analyst, 1990, 115, 111-116.

11. Bosch-Reig F, Camppins-Falco P and Verdu-Andres J, Talanta, 1992, 39, 1.

12. Bosch-Reig F, Campins-Falco P, Hernandez B H and Sevilano-Cabeza A, Anal Chim Acta, 1992, 257, 89.

13. Mannan Hajimahmoodi, J Food Anal Methods, 2008, 1, 214-219.

14. Eskandari H and Bagherian Dehaghi G, Microchim Acta, 2004, 146, 265.

15. Bosch-Reig F, Campins-Falco P, Sevillano-cabeza A, Herraez-Herhnandaz R and Molins-legua C, Anal Chem., 1991, 63, 2424.

16. Bosch-Reig F, Campins-Falco P and Verdu-Andres J, Anal Chim Acta, 1993, 283, 831-844.

17. Campins-Falco P, Bosch-Reig F and Verdu- Andres J, Anal Chim Acta, 1992b, 270, 253-265.

18. Campins-Falco P, Bosch-Reig F, Verdn-Andres J and Molins-legua C, Anal Chim Acta, 1995, 302(2-3), 323-333.

19. Bosch-Reig F, Verdu- Andres J, Campins-Falco P and Molins-legua C, Talanta, 1994, 41, 39-52. 


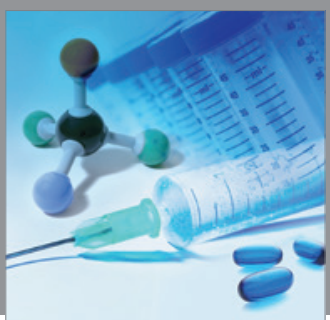

International Journal of

Medicinal Chemistry

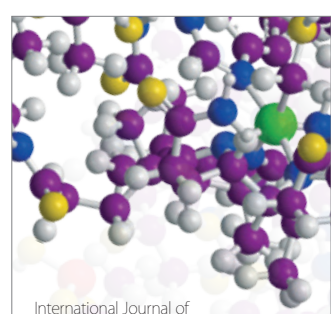

Carbohydrate Chemistry

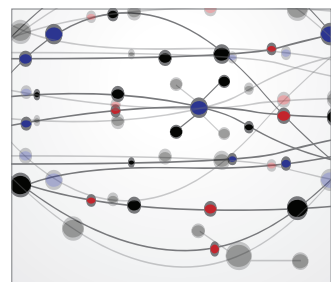

The Scientific World Journal
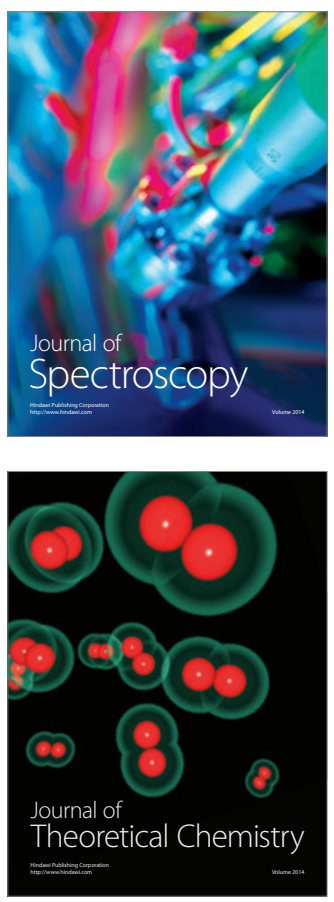
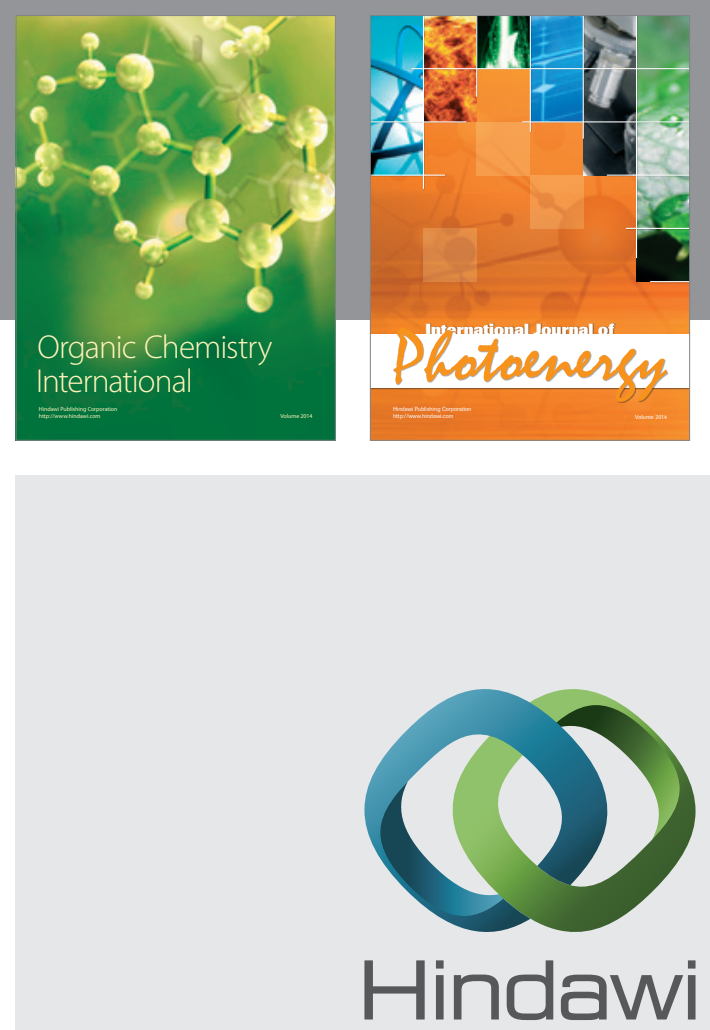

Submit your manuscripts at

http://www.hindawi.com
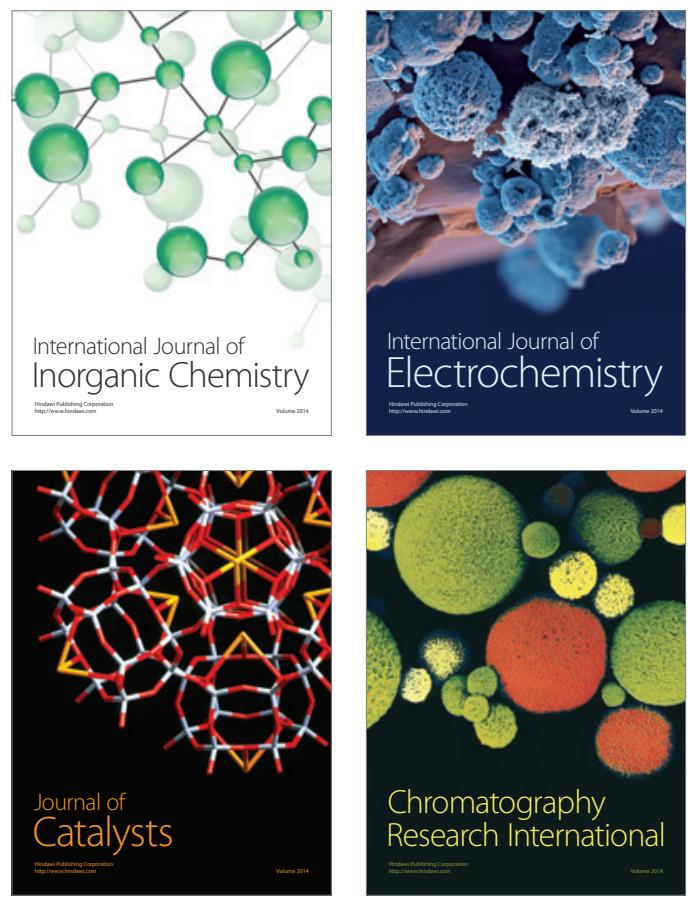
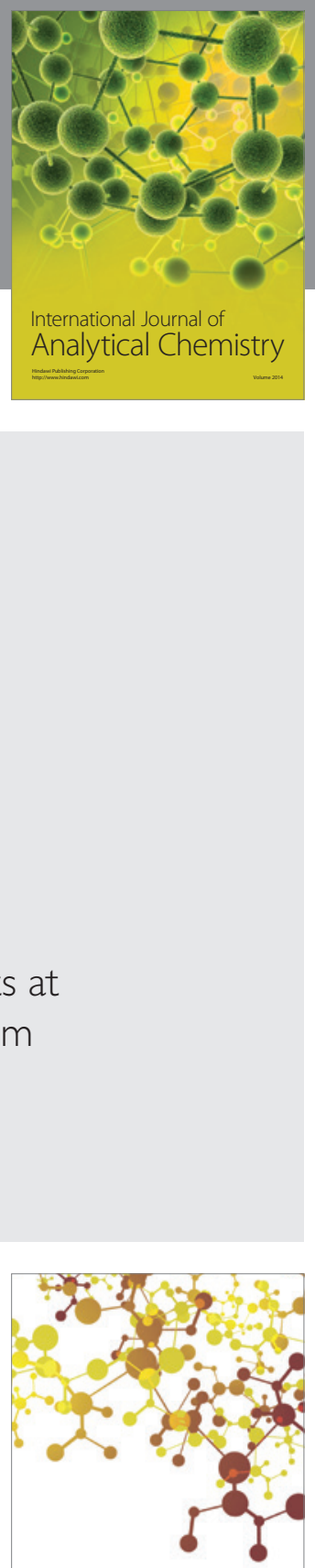

Journal of

Applied Chemistry
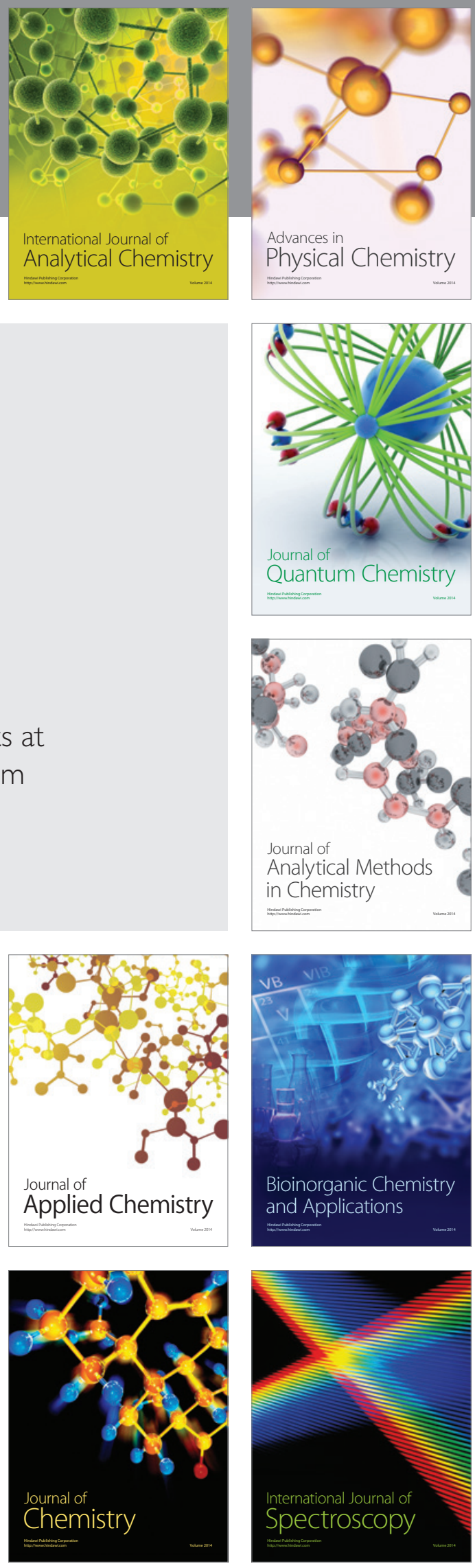